\title{
Peptidyl-Prolyl Cis-Trans Isomerase F, Mitochondrial
}

National Cancer Institute

\section{Source}

National Cancer Institute. Peptidyl-Prolyl Cis-Trans Isomerase F, Mitochondrial. NCI

Thesaurus. Code C118236.

Peptidyl-prolyl cis-trans isomerase $F$, mitochondrial (207 aa, $\sim 22 \mathrm{kDa}$ ) is encoded by the human PPIF gene. This protein is involved in the regulation of both cell death and protein folding. 